\title{
O ESPELHO EM "JOGO DA CABRA CEGA": UMA PERSPECTIVA PSICANALISTA SIMBOLICA. *
}

\author{
Amint Boainain Hauy ** \\ O homem não pode permanecer muito tempo em \\ estado consciente; sempre lhe é necessário descer ao \\ seu inconsciente, pois é all que ele tcm suas raizes. \\ Goethe.
}

\section{Introduçāo}

Sabe-se que toda obra de arte permite uma infinidade de leituras possiveis, a partir de seus dados exteriores; e tanto mais rica será ela quanto mais perspectivas de análise oferecer. Assim É o Jogo da cabra cega de José Régio 1, [romance] publicado primeiramente em Portugal, quando a geração da Presença começava a impor o seu idearium esteticista, espiritualizante e culturalista.

Considerando a sua complexidade intrínseca e extrínseca, a riqueza de coordenadas sociológicas e psicológicas, em cujo ponto de encontro o homem se debatc. marcado por esse dualismo do horizontal e do vertical. essa obra pode ser interpretada num enfoque psicanalítico, como uma simbólica e literária "psicanálise" de um ser, obsessivamente voltado para a busca do "Eu" auténtico.

Elemento de destaque da geração presencista, - a geraçāo portuguesa preocupada com a desmistificação das aparências do real-concreto, para redescobrir o oculto, José Régio cm Jogo da cabra cega.

* Fragmento do trabalho elaborado sob a orjentacáo da Prof Nelly Novag" Coclho durante o curso o Presencismo, área complementar ncis cursos de Mestrado em Lingua Portuguesa na Universidade de Săo Paulo tendo recebi. do concelto A (excelente).

** Mestre em Lingua Portuguesa pela Univergidade de Sūo Paulo com a tey, Maestre Nicolas a mau Cuydar de Afonso de Coton (18/04/75), Amini Baainain Hauy leclona Lingua Portuguesa na Faculdade de Fllosofin, Ciencias e Lc. tras de Ribeiråo Preto e na Faculdade de Filosolia, Ciencias Humanas c Lctras da Unirersidade de S\&o Paulo.

1 ReGIO. Jose, Jogo da cabri cega. 3. ed. Lisboa. Brasilia Ed., 1971. 435 p. 
procura apreender o homem nas malhas do mundo interior e, sob forte influência freudiana, desenvolve esse apreender através de um processo que se pode chamar de psicanálise de um "eu" simbolicamente projetado nos "outros".

O Jogo da cabra cega alćm disso, foi escrito em uma época de extraordinária euforia com as recentes descobertas da Psicanálise. E tão marcante deve ter sido a influência de psicólogos seus contemporâneos, principalmente Freud, na formaçāo intelectual de José Régio, que passagens de seu romance projetam situações, nomes, conceitos, enfim, vários princípios das teorias psicanalíticas da época, na visāo estilizada da realização artística.

Confronte-se, por exemplo, o Jogo da cabra cega (que é em síntese, o conflito dialético do "eu" e do "inconsciente") com a obra de Freud, no que se refere ao narcisismo, à agressividade, aos sonhos, ao inconsciente, à rcpressāo, à introjeção, à mania de perseguiçāo, e tantos outros princípios psicanaliticos fundamentais, literariamente explorados por José Régio.

Quanto à influência de Jung, mesmo considerando ser ele desconhecido em Portugal naquela época, o que é muito provável, dada a dificuldade de tradução do alcmão, podemos dizer que a sua presença se faz sentir nessa obra. E isso significa que as vivências de um determinado momento, a sensibilidade de uma geração, evidentemente transparecem em todas as expressōes de cultura. Assim, se a Psicanálise faz a teorizaçāo dessas vivências, a Literatura as expressa artisticamente.

Associando-se às imagens criadas pela introversāo, percebemos nessa obra, as imagens arcaicas (anima, o Sombra, o herói interno, o "deus psicológico" do inconsciente coletivo) e a mandala de Jung.

Para exemplificação citamos apenas algumas passagens que nos levam a Jung, uma vez que esta obra oferece vasto material para um minucioso estudo dessa perspectiva:

Página 118 - "Tendo o segredo de rodopiar como um pião, dentro do mesmo círculo, tinha ainda o de me arrastar com elen.

Página 374 - "Só mais tarde, quando da observação apaixonada, partidarista do meu círculo ou do meu caso ascendesse à contemplaçāo da própria natureza humana" (confronte-se $\operatorname{com}$ a mandala $=$ símbolo "mêsmico" — Selbest de Jung).

Página 322 - . . "haverá, ou não, em todos os homens, esse fundo sinistro?

Página $368-\ldots$ "ia descobrindo, em mim e nos outros aquele monstro que sendo afinal, a bestialidade do homem, existe em todos os homens".

Página $358-\ldots$ "se a luta me feria tanto, era porque a instintos e scntimentos meus se opunham outros também meus; ou tornados meus pelos séculos e séculos que me tinham modelado... Quer tudo isto dizer que em tudo era eu solicitado por tendênclas opostas". 
Página $344-\ldots$ "eu compreendia que o meu demónilo vencera"...

Página 256 - "Mas, às vezes, um Anjo se erguia a meu lado afugentando os meus demónlos (eu agarrava-me agora - o termo é brutal, mas verdadeiro - eu agarrava-me agora ao mito do meu Anjo...)".

Página 192 - .. "como explicar-lhe que o meu riso se desencadeia cm mim tão superior à minha pobre vontadc, tão inacessivel à minha razão?"

Coincidência, ou nāo, a "Dora" do caso narrado por Freud e a "Dora" de Pedro Serra têm a mesma "conotaçāo psicológica".

"Quando, no dia seguinte, comecei a procurar um nome para uma pessoa que não devia conservar o que the era proprio, só um me ocorreu: Dora 2.

A Dora de Pedro Serra é também, considerando o "contexto psicológico" que é o campo desse trabalho, um produto da introversão, instrumento que realiza a libido reprimida.

Poder-se-ia afirmar, em síntese, que nessa obra de oposiçāo de dois mundos: o do "eu" e do "inconsciente", do "convencional" e do "anti-covencional", a influência de Freud se faz sentir principalmente no "conflito" e a de Jung, suposta, pressentida, na libertação pelo encontro com o "deus psicológico".

Página 377 - "Assim, através do conhecimento de mim, se me revclava a humanidade. E assim me revelou Deus!"

Método de exploração do psiquismo humano e, principalmente, uma terapêutica para certas neuroses. a psicanálise scm dúvida acabou por invadir todos os domínios da atividade e da cultura humana e sobretudo $a$ arte.

E pois inegável que as várias tendências e caracteristicas de uma determinacia época inter-relacionam-se e, de uma forma ou de outra, alteradas ou dissimuladas, enriquecidas ou deformadas, projetam-se na criaçāo da obra de arte.

Assim, estudando o espelho nesse romance, numa perspectiva psicanalítica simbólica, como um dos recursos liberadores do inconsciente no processo de recomposição do "eu" fragmentado, procuramos mostrar, inicialmente a "conotação psicológica" do espelho na obra de Freud, Jung. Jacques Lacan e Melanie Klein. Em seguida procuramos estudar o simbolismo do espelho no Jogo da Cabra Cega.

Se nos lecidimos pela perspectiva da Psicanálise para a interpretação desse romance, fugindo assim às exigências da crítica puramente literária, foi pelo fato de termos sentido sua extraordinária projeçāo e indiscutível influência na obra estudada. Se na realidade aparente da estrutura narrativa projetamos uma realidade psíquica, de cstrutura profunda, tivemos em mente mostrar como princípios psicanalíticos podem, revestidos da sensibilidade e da criatividade do

2 FREUD, Slgmind. Obras completas. Rlo de Janelro, Delta, 1959, v. 1. p. 570 . 
autor, transparecer na criação artística pois, evidentemente, como afirma Casais Monteiro: "a verdadeira objetividade, em todos os planos da cultura humana nos permitirá algum dia reconhecer que a ciência e as "humanidades" nāo sāo universos irremediavelmente opostos". 3

\section{O ESPELHO segundo a Interpretaçāo de Freud, Jung, Lacan e Melanie Klein}

No Jogo da cabra cega, um dos recursos liberadores do inconsciente, bloqueado pcla coerção moral do Sistema social, ́́ o espelho, elemento estrutural de importância básica para a compreensão dos conflitos estabelecidos na obra.

Em várias teorias psicanalíticas o elemento espelho é também interpretado como passível de exercer uma função liberadora.

Como se sabe, a psicanálise, como método de interpretação, procura estabelecer as relaçōes de causa e cfeito. Segundo Freud. "a difurenciação do psíquico em consciente c inconsciente $\dot{e}$ a premissa fundamental da psicanálise". Seu conceito de inconsciente tem, como Iponto de partida, a teoria da repressāo. O reprimido é o protótipo do inconsciente 4 .

Para descobrir essas atitudes profundas de reação que se ocuitan sob aparente caráter que o indivíduo constrói, a psicanálise freudiana usa determinados recursos técnicos como: estudo dos gestos. expıessöes, sonhos, letra, etc.

A duplicação realizada pelo espelho corresponde na obra de Freud à projeção, ao narcisismo, ao sonho, à introversão. Dai que esses três elementos se inter-relacionem constantemente.

Documentando cssa interpretaçāo temos:

"Um sonho é, portanto, uma projeção para o exterior de um processo anterior" 5.

"Por esta razão sc esforça tanto em projetar para o exterior aquilo que cm seu interior lhe é motivo de desprazer" 6 [(vol. V-487)].

"A transformação no contrário decompōe-se, quando a submetemos a um detido exame, em dois processos diferentes: a transiçāo de um instinto de atividade à passividade, e a transformaçāo de conteúdo. Por exemplo, os pares antitéticos "sadismo-masoquismo" e "prazer visual-exibição". A transformação no contrário atinge somente os fins do instinto. O fim ativo - atormentar, ver - c substituído pelo

3 CASAIS monteiro, A. A palarra essencial. São Paulo, Ed. Naclonal, 1965. D. $5 E$.

4 FREUD, $\vee .6$, p. 171 .

5 Ibid., v. 5, p. 479.

6 Ibid., v. 5, p. $48 i$. 
passivo - ser atormentado, ser visto. (...) A exibição contém em si a contemplaçāo do próprio corpo" 7 .

"A regra técnica fundamental - iniciamos a tratamento convidando o paciente a se colocar na situação de um auto-observador atento e desapaixonado, limitando-se a ler a superficle de sua consciencia e obrigando-o, em primeiro lugar, a uma absoluta sinceridade" 8 .

"Tudo o que pode tornar-se objeto de nossa percepção Interior é virtual, como a imagem produzida pela penetração dos raios luminosos nas lentes dos óculos. Os sistemas que em si não são nada de psíquico e nunca são acessiveis à nossa percepção psíquica, podem ser comparados às lentes dos óculos, as quais projetam a imagem.

A síntese gráfica leita por Jacobi ilustra a posiçāo que, nos diversos planos da indivicualidade, adquirem seus principais elementos de acordo com a doutrina de Yung.

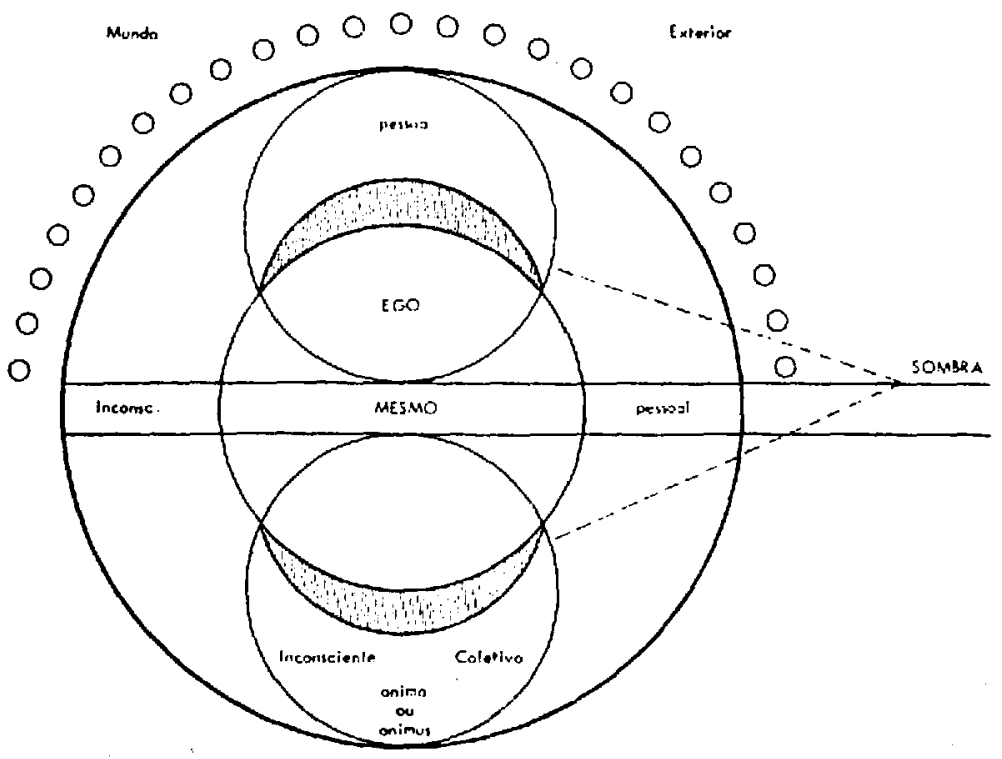

Esquema dos setores e núcleos energéticos integrantes do Ser Humano. (Mira $Y$ Lopes, Em. Os fundamentos da psicanalise, Rio de Janeiro, Científica, s. d. p. 190).

7 FREUD, v. 5, p. 410.

8 Ibid., v. 8, p. 397 .

Letras, Curitiba, 124] 21-34 dez. 1975 
Prosseguindo nessa comparação. a censura situnda entre os dols sistemas corresponderia a refraçăo dos ralos ao passarem para um novo meio" 9.

Em Os fundamentos da Psicanalise, Mira Y Lopes, referindo-sc ao mandala de Jung afirma que "o simbolismo mandálico parece uma espécie de núcleo atômico. Podemos, pois, considerá-lo como a imagem especular, real, isto é, efetiva, de uma atitude de consciência que não pode formular nem seu objetivo nem seu propósitu. ': cuja atividade. em virtude de tal renúncia, se acha compleiaresente projetada no centro virtual do mandala" 10 .

Jacques Lacan, também discípulo de Freud, participando do XVI Congresso Internacional de Psicanálise (1936) apresenta a Comunicação, O estágio do espelho. Em 1948, O estáglo do espelho como formador da função do "eu".

O estudo desta problemática apresenta alguns temas fundamentais: o papel do espelho na constituição do sujeito e a significação do próprio corpo.

"Il y suffit de comprendre le stade du miroir comme une Identification au sens plein que l'analyse donne à ce terme: à savoir la transformation produite chez le sujet. quand il assume une image dont la prédestination à cet effet de phrase est suffisamment indiqué par l'usage, dans la théorie. du terme antique d'imago" 11.

"Le stade du mirolr donne la régle de partage entre l'imaginaire et symbolique à ce moment de capture par une inertie historique dont tout ce qui s'autorise d'être psychologie porte la charge. fût-ce par des voies à prétendre s'en dégager" 12 .

Os problemas debatidos por Lacan em torno do estágio do espelho são estranhos às investigaçōes freudianas, entretanto, é possível encontrar certa articulação de seus conceitos com a obra de Freud, se consideramos os ensaios "Psicologia das Massas e Análise do Eu" ou "Introdução ao Narcisismo", nas quais Freud submete o "eu" a uma dupla referência.

Melanie Klein também cita em seus trabalhos o espelho, especialmente no que diz respeito à relação da fantasia do corpo fragnentado com a fase paranóica e com as fantasias que a caracterizam.

Encontramos ainda. frequientemente, o espelho no vocabulário específico da psiquiatria. Por exemplo, no folheto n." 7: Esquizofrenia,

9 FREUD, v. 3, p. 388.

10 MIRA $Y$ LOPEz, E. On fondamentos da Psicańlise, Rlo de Janelro, Cientitica, s.d.

11 LACAN, J. Ecrits. p. 94. Apnd PALMIER, Jean Michel. Jacqner Lacan, lo simbólico y lo imaginário. Buenos Alres, Proteo, 1971 p. 21.

12 Ibld., p. 69 apud op. cit. p. 41. 
da série "Elementos de Psiquiatria para o Clínico Geral", publicaçōes da "Roche", no capítulo de "Experiências de Despersonalização":

"esse sinal clássico do espelho"... 13

E, mais adiante, referindo-se aos disturbios do caráter e da afetividade:

"A regressão manifesta-s` ainda em comportamento bulímico, tóxico-maníaco, de tentativas narcisísticas dlante do espelho" 14

\section{O simbolismo do espelho na literatura}

Na literatura de todos os povos, em diferentes épocas, o simbolismo do espelho tem sido bastante explorado.

Em sua obra - Psicologia e Literatura 15 - Dante Moreira Leite estuda o espelho em duas obras de épocas diferentes: uma que encontrou expressāo na teoria freudiana da personalidade e outra, na teoria jungiana.

- Espelho (Esboço de uma Nova Teoria da Alma Humana) de Machado de Assis, também apresenta o homem diante do espelho: "Cada criatura humana traz duas almas consigo: uma que olha de dentro para fora, outra que olha de fora para dentro"... 16 O Espelho de Machado de Assis sugere que a individualidade coincide com o que se poderia denominar o "eu social", e abaixo do qual a personagem nada consegue encontrar. Se lhe faltam os outros - nos quais se vé - também não poderá identificar-se, e esse processo de autoidentificação só ocorre quando, diante do espelho, adquire a sua fisionomia socialmente aceita, pois esta é, na realidade, a única que possui.

De outro lado a teoria de Machado de Assis contém outro elemento importante. correspondente à idéia de desmascaramento das aparências da pessoa. Essa tendência supōe uma oposição fundamental entre os impulsos individuais e as exigências da sociedade a que a pessoa se submete. Essa tendência foi a que - dentro, evidentemente, de outras premissas teóricas, - encontrou expressāo na teoria freudiana da personalidade.

Em $O$ Espelho, de Guimarães Rosa, a personagem conta suas experiências diante do espelho; depois de mostrar que este nem sempre reflete a mesma imagem, lembra o medo que o espelho sempre inspirou aos primitivos; - "não haveria em mim uma existência central. pessoal, autónoma?" Há aqui uma concepção psicológica que, sob al-

13 ESQUIZOFRENIA. In: ELEMENTOS de pgiqulatria para o clínico geral. s.1., Roche, a.d. n. 7 .

14 Ibid.

15 LeITe, Dante Moreira. Paitcologls e literatura, 2. ed. Băo Paulo, Ed. Nacional/Ed. da USP. 1967. $256 \mathrm{p}$.

16 MACHADO DE ASSIS. Joaquim Maria. 0 espelho. In: svulsos. Rio de Janeiro, W.N. Jackson, 1938. p. 259-76. 
guns aspectos, pelo menos, se aproxima da teoria jungiana da personalidade". 17

\section{O espelho em o Jogo da cabra cega}

O espelho ć um elemento estrutural importante para a compreensão do romance de José Régio, - romance que reflete a oposição de dois mundos: o do "eu" e o do "inconsciente", o drama de um ser obsessivamente atormentado pela ânsia da unidade psicológica perdida: suas fantasias, scus conflitos c sua recuperação. $O$ espelho torna-se o fator ou o índice visível do desdobramento do "eu" em suas múltiplas "realidades psiquicas".

Vejam-se alguns exemplos desse desdobramento, principalmente na expressão do conflito íntimo da personagem central. Pedro Serra, e no conflituoso relacionamento entre os amigos que compunham o grupo: Luís Afonso. José Baía, Celestino, o Sombra c o elemento desagregador do Grupo, - Jaime Franco. Nos momentos em que o "cu" parecia desdobrar-se em "outros"... fatalmente temos a presença reduplicadora do espelho.

"Abandonava-me [Pedro Serra] além disso a um jogo muito meu predileto: Começara de experimentar no espelho a minha mobilidade fisionômica, c ia etiquetando as minhas máscaras conforme os sentimentos, paixōes ou instintos sugeridos. Fazia isto quase a frio, bastante lisonjeado ora pela perfeição, ora pela naturalidade, ora pela originalidade do meu trabalho" 18.

O espelho aparece ainda como instrumento de liberaçāo como que hipnótica. Veja-se a cena do "Café do Preto", quando o espelho, refletindo as luzes ora ofuscantes, ora difusas, exerce em Pedro Seria. já estimulado pela ânsia de libertaçāo, uma funçāo hipnótica, desencadeadora do inconsciente e libertadora do "eu". (A hipnose foi o método usado inicialmente por Freud que depois o substituiu pela auto-observação) .

"Se o excesso de auto-análise é ainda doença, eu [Pedro Serra] apresentava mais esse sintoma doentio 19 L...] eu era espectador critíco de mim próprio. [...] ainda nāo perdera consciência do meu estado de perversão nervosa 20.

"Todo descjo é cm mim fugaz se o não alimenta a fome dos meus monstros interiores; se o nāo recoze o fogo da Imaginação livre e louco" 21 .

17 GUIMARAES ROSA. Joåo. O espelho. In: Primeiras estória's. rio de Janelro, J. Olympio, 1968. p. 70.78 .

18 REGIO, Jogo...p p. $15 \vec{i}$.

19 Ibjd., \. 380 .

30 Ibid., 1.57 .

21 Ibid.. v. 181 . 
$\mathrm{Na}$ interpretaçāo de A. Austregésilo, "o sono hipnótico manifesta-sc pelo máximo de sugestibilidade. E pela intençāo, ordem, autosugestāo ou pelo próprio desejo do individuo, que se consegue adormecer. A fixação de objetos luminosos, objetos fixos, são artifícios que aumentam ou canalizam a sugestibilidadc que se manifesta como finalidade no sono" 22.

Neste sentido, certificamo-nos de que em Pedro Serra havia uma instintiva predisposiçāo para a liberaçāo do "eu".

"Eu experimentava uma necessidade impaciente e desenganada de me descartar de mim próprlo. [...] A sugestão foi tão forte... [...] Mas, cstes jogos de imaginaçāo a que me dou frcqüentemente... [...] Aquele espelho barato, aquela novidade sensacional (Mlle. Dora) e aquela fotografia lúbrica exasperavam-me... Em tudo aquilo havia como que um eco do que na minha vulgaríssima vida mais me desgosta. E quem perdoa reencontrar fora de si o que já em si detesta?" 23.

Com relaçāo a esses processos de fuga do "eu", pela fantasia. Freud diz que "a fantasia ć tolerada durante um longo periodo até que. repentinamente, e na maioria das vezes, em conseqüicncia de uma intensificação de sua carga afetiva. surge o conflito entre a fantasia c o Eu, com todas as consequèencias" 24 .

Em Jogo da cabra cega, temos esse momento quando surge a necessidade do "jogo da verdade" entre os elementos do Grupo, e principalmente em Pedro Serra, que expressa bem a consciência dessa necessidade quando diz: "Pude, entāo, refletir sobre os vários acidentes ou lases da minha vida, procurando coordená-los como quem procura arrumar um casarão devastado". 25

A essc respeito, diz Freud: "Devemos convir em que todos os atos c manifestaçōes que percebemos em nós mesmos (sem que saibamos introsá-los com o resto de nossa vida ativa) devem ser considerados como se pertencessem a outra pessoa $\mathrm{c}$ devem ser explicados por uma vida animica a ela atribuida. Devemos ter $\mathrm{cm}$ conta, que conforme nos revela a investigação psicanalitica, uma parte de tais processos latentes possui caracteres c particularidades que nos parecem estranhos, incriveis e totalmente opostos às qualidades da consciência por nós conhecidas. Tudo isto leva-nos a modificar a conclusāo do processo dedutivo que aplicamos à nossa própria pessoa, no sentido de já nāo admitir em nós a existência de uma segunda consciência, mas a de atos carentes de consciência" 26.

IU AUTREGESILO, A. As torgus curativas do espírito. Rio de Janciro. Francisco Alves, 1920. p. 76.

23 REGIO, $O$ jogo..., p. 12.22

24 FREUD, v, 6, p. 16.

25 REGIO, Jogo..., p. 380 .

26 FREUD, v, 5, p. 444. 
Como vemos, além de sua carga hipnótica, o espelho em Jogo da cabra cega, permite também o desdobramento do "eu", na libertação do inconsciente reprimido, projetando-se no "Grupo". Na verdade, o Mundo é um grande espelho que devolve a cada um de nós a sua própria imagem. Assim é que, numa perspectiva psicanalítica simbólica. concluímos que para além da realidade social da estrutura narrativa, o "Grupo" pode também ser interpretado como projcçāo de uma realidade psíquica inconsciente $(=0$ id) $\mathrm{com}$ a qual o Ego entrará $\mathrm{cm}$ conflito. No evoluir do conflito entre Pedro Serra e os demais, percebemos que os "outros" são aquilo que ele encontra como imagem de si próprio.

"Essa imagem é que me copia", diz Pedro Serra 27.

"Para que um homem compreenda tudo, necessário é que seja tudo" 28.

Portanto. na efabulação narrativa, a função desse "Grupo" (= id) é operar a descarga das excitaçōes (energia ou tensāo) desencadeadas em Pedro Serra ( $=$ ser atormentado por estimulaçāo interna e externa). Da mesma forma, cada componente do "Grupo" é uma "máscara diante do espelho", que libera e realiza o reprimido. Comprovam-nos isso a necessidade de "sonhar mistérios", o "jogo fisionômico" e a imaginação desenfreada que caracterizam o personagem-narrador.

"E torci-me numa espécie de gargalhada muda, convulsiva, que não era senão a minha necessidade de libertar qualquer coisa que não cabia em mim" 29.

"...e jogado no tumulto do meu ser que se partia, repartia, emaranhava, multiplicava, desfazia e tentava refazer" 30 .

"Escolheste bem o teu lugar. Bem e mal: porque os espelhos têm sobre ti a sedução diabólica da ribeira de Narciso. Acabarás um dia precipitando-te de cabeça no cristal... E será. sem dúvida, um suicídio digno das tuas máscaras". 31

Celestino, José Baia, Luís Afonso c... o Sombra sāo, sem dúvida, as personagens que no plano subjetivo representam projeçōes das tendências reprimidas no inconsciente, aspectos do Eu dividido. Jaime Franco é o "caudilho", a soma das fantasias inconscientes personificadas, projeçāo e realizaçāo integral de todas as perspectivas multifacetadas do Eu, através do espelho. Jaime Franco é a confissāo das tendências opostas que coexistem em todos os homens. "E a provo-

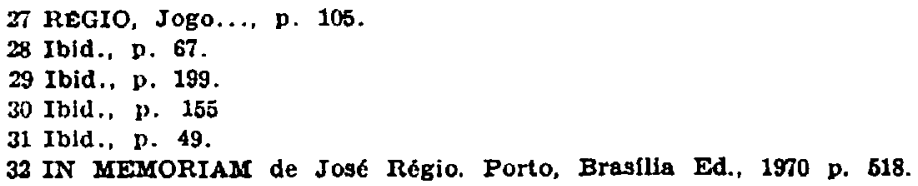


cadora exibição da totalidade das grandezas e das misérias de que um homem é feito e que na sua alma se ocultam e se degladiam" 32.

"Um monstro se revelara em mim plenamente - um desconhecido de quem, até hoje, só recebera vagos avisos. Maldito seja ele! bradei, pensando em Jaime Franco" 33.

"Tenho medo de ser só, porque tenho medo de ser doido!" 34.

Confrontando as características e as atitudes dos componentes do Grupo, concluir-se-á que, embora diferentes entre si, no conjunto todas revelam a projeção do inconsciente reprimido.

Na sondagem do Eu, o espelho é ainda o elemento poético de natureza visual que caracteriza o dualismo entre "mundos" que se observam $c$ se agridem pelas antíteses. que se interrogam numa dialética de busca da unidade psicológica do ser humano (forjado pelos instintos) e o do homem social (bloqueado pelo convencionalismo das relaçōes). "Não é ele condicionado no mínimo dos seus movimentos?" pergunta Pedro Serra ${ }^{35}$.

E também significativo o fato de o elemento espelho aparecer com bastante freqüência até o capitulo XVII (pouco mais da metade do livro), citado exatamente vinte e quatro vezes, e desaparecer por completo da narrativa até o final da obra. Corresponde essa peculiaridade a uma mudança na eclosão dos conflitos. E que o "dualismo das faces" (cf. cap. XVII - Jogo da Cabra Cega) cede o palco ao "dualismo das idéias" (Cap. XVIII - Discours de la méthode). A desintegração do "eu" esquartejado pelos delírios da "imaginação louca" fora feita até entāo (cap. XVII) por estimulação interna (ânsia de autenticidade) e por estimulação externa: o espelho.

Diz José Régio, em artigo publicado no número inaugural da revista Presença: "Em arte é vivo tudo o que é original. E original tudo o que provém da parte mais virgem, mais verdadeira e mais intima duma personalidade artística" 36. As "máscaras" em Jogo da cabra cega foram vividas sensorialmente. A partir do cap. XVIII ("Discours de la Méthode") a sua vivência torna-se "intelectiva" e a reintegração das múltiplas faces ( $=$ o Grupo) na unidade psíquica do Eu (= Pedro Serra) passa a ser feita no campo da dialética.

A libertação, afinal, torna-se aparente mas não muito convincente. o que talvez tenha levado o autor a concluir o romance com a frase:

33 REGIO. JOgO.... D. 167.

34 Ibid., p. 98.

35 Ibid., p. 202.

36 SIMós, Jolo Gaspar. Hintório do Movimento da APresengas. Coimbra, Atlantida. 1958. p. 79. 
"Em que provisoriamente se dá por terminado este livro". (Note-se que Jaime Franco reaparecerá como personagem em Vidas săo Vidas).

No nivel da linguagem, o indice do dualismo, que alimenta a mensagem do romance, é o uso abusivo das adversativas e das alternativas. Feito um levantamento estatístico das conjunçōes coordenativas nas 430 páginas do romance, verificou-se que (excetuando-se as aditivas, cujo cmprego é inevitável na narrativa), resulta que entre as 1.614 conjunçōes coordenativas usadas, 894 são adversativas e 624 , alternativas, o que vem reafirmar a coerência orgânica do romance, cuja linguagem reflete perfeitamente o conflito dos contrários dentro da mesma realidade psíquica.

"...o meu primitivo dilema: ou eu ou eles, depois visto a estoutra luz: ou o meu eu social ou o meu eu anti-social, ou o meu eu moral ou o meu eu imoral" $3 i$.

"Mas o paradoxo nāo é uma das expressōes da verdade?" 38.

"O meu estado mais definivel era uma alternativa"... 39.

"... em tudo era eu solicitado por tendências opostas" 40.

$\mathrm{Na}$ dialética de dismistificação do convencionalismo, as adversativas e alternativas revelam que as faces antagônicas da mesma realidade, cmbora se opondo, se completam: Bem e Mal, Anjo c Demônio. Santa e Prostituta, Amor e Odio, Verdade e Mentira, Sinceridade e Cinismo. Mas dão, sobretudo, a tônica do dilema.

Concluindo: O Jogo da cabra cega, obra de autenticidade vivencial, de questionamento das convençōes morais, de obstinada afirmação de uma personalidade. de constataçāo da dualidade que marca o ser humano, de visualizaçāo do mundo pelo Eu e principalmente de busca da unidade psicológica do Eu fiagmentado, define-se como uma das obras mais representativas da geração da "Presença" e reủne, segundo os idcais do movimen:o, as caracteristicas da verdadeira obra de arte.

"A obra de arte é simultaneamente intençāo profunda e jogo, imitação aparente e transfiguraçāo real" 41.

37 REgIO. Jogo..., p. 366.

39 Ibid., n. 118.

39 Ibld., p. 216.

40 Ibid.. D. 368.

41 REGIO. J. Trés ensaios sobre arte. Lisboa. Portugália, 1967. p. 64. 


\section{REFERENCIAS BIBLIOGRAFICAS}

AUSTREgesilo. A. As torgas curativas do espirito. Rio de Janeiro, F. Alvea, 1926.

AYER, A.J. Ru e os outros. In:

Lisboa, Ulisseia, s.d, p. 145-80.

CASais MONTEIRO, A. A palavta exsencial. São Paulo, Ed. Nacional, 1965. $181 \mathrm{p}$.

DUCASSE, Plerre. As rrandes correntes da fllosofia. 3. ed. Lisboa, Europa. América, 1963. $135 \mathrm{p}$.

ELEMENTOS de psiquiatria parn o clínico Beral. 3.1., Roche, s.d. n. 2.7.

FREUD, SIgmund, Obras complotas. Rlo de Janeiro, Delta, 1359. 8 v.

GUIMARás ROSA, J. Primeirus estórins. Rio de Janeiro, J. Olympio, 1968. $176 \mathrm{p}$.

IN MEMCRIam de José Regio. Porto, Bragilla Ed., 1970. 558 p.

JUNG, C.G. $O$ en desconhecido. Rio de Janeiro, Fundo de Cultura, 1961. 131 p. Tipos psicologicos. Rio de Janeiro, Zahar, 1967. 567 p.

LEITE, Dante Moreira. Psicologia e llteratura. 2 ed. SGo Paulo, Ed. Nacional Ed. da USP, 1967. $256 \mathrm{p}$.

LISBOA, Eugenio. Jose Rigio; nota bio-bibliográfica, exame crítico e bibliogra. 1ia. Porto, Tavares Martins, 1957. $201 \mathrm{p}$.

MACHADO DE ASSIS, J.M. Papels avulsos. Rio de Janeiro, Juckson, 1938. 318 p.

merimaN, Jefrey. Entre psychanalyse et psychocritique. Poétique, Paris (3): 365.83, 1970.

MIRA $Y$ LOPEZ, $E$. Os fundamontos da psicanálise. Rjo de Janeiro, Cientifica. s.d.

- Paiquiatria básica. Buenos Alres, El Ateneo, 1948.

MUELLER, Fernand-Lucien. A psicologia das profundezas. In: —____ His Lúria da psicologia. São Paulo, Ed, Naclonal, 1963. p. 357.78.

PACHeCo, Virgillo Camnrgo. Inbitantes do inconsclente. Săo Paulo, Anhembi. 1959. $167 \mathrm{p}$.

PALMIER, Jean Michel. Jacques Iacan, lo simbolico 5 lo imaginarlo. Buenos Alres Proteo, 1971. 154 p.

QUadroB, Antonio. Critica verdade. Lisboa, Clássica, 1964, 281 p.

REGIO, José, Ensaios de interpretasio crítlea. Lisboa. Portugialia, 1964. 244 p.

- Jogo da cabra cega. 3 ed. Lisbon, Brasilia Ed., 1971. 435 p.

. Trts ensaios kobre urte. Llsboa, Portugália, 1367. $170 \mathrm{p}$

SIMöES, Joğo Gaspar. Histórin do movimento da Presença. Coimbra, Atlantidn, 1958, $295 \mathrm{p}$.

TORRE, Guillermo de. Hlst6ria das literataras de vanguarda. 2. ed. Lisboa, Presença, 1972. v. 1.3.

\section{Resumo}

Escrito numa época de extraordinária euforia com as recentes descobertas da Psicanálise, o Jogo da Cabra Cega revela marcante influência de psicólogos contemporâneos do autor, principalmente Freud e Jung.

Procurando apreender o "homem" (Pedro Serra) nas malhas do mundo interior, José Régio, sob forte influência freudiana, desenvolve esse "aprecnder", através de um processo que se pode chamar de psicanálise de um "eu" simbolicamente projetado nos "outros". Assim é que, visto alćm da realidade social da estrutura narrativa, o "grupo" é interpretado como projeção de uma realidade psiquica inconsciente 
( = o id) com a qual o Ego entra em conflito. E, o elemento estrutural que favorece essa projeção é o espelho, estudado também em várias tcorias psicanalíticas (Freud, Jung, Jacques Lacan e Melanic Klein) como passivel de exercer uma função liberadora.

A "conotação psicológica" do espelho é enfatizada no Jogo da $\mathbf{C a}$ bra Cega, por sua função hipnótica, liberadora do inconsciente bloqueado pela coerçāo moral de Sistema social.

$\mathrm{Na}$ efabulação narrativa, a funçāo do "grupo", resultante da multiplicação do "eu" pelo espelho, ć operar a descarga das excitaçóes (energia ou tensāo) desencadeadas em Pedro Scrra (= ser atormentado por estimulação interna e externa).

Da mesma forma, cada componente do "grupo" é uma máscara diante do espelho, que libera e realiza o reprimido.

\section{Riassunto *}

Scritto in un'epoca di straordinaria euforia per le recenti scoperte della Psicanalisi, il Jogo da Cabra Cega denota notevole influenza di psicologi contemporanei deli'autore, principalmente Freud e Jung. Cercando di cogliere 1"'uomo" (Pedro Serra) nelle maglie del mondo interiore, José Régio, sente forte influenza freudiana, sviluppa questo "cogliere" attraverso un processo che può chiamarsi psicanalisi di un "io" simbolicamente proiettato negli "altri". Cosicché, visto al di là della realta sociale della struttura narrativa, il "gruppo" è interpretato come proiezione di una realtà psichica inconsciente $\left(=l^{\prime} l d\right)$ con la quale l' Ego entra in conflitto. L' elemento strutturale che favorisce questa proiezione è lo specchlo, studiato anche in varie teorie psicoanalitiche (Freud, Jung. Jacques Lacan c Melaine Klein) come passibile di svolgere una funzione liberatrice. La" connotazione psicologica" dello specchio è messa in enfasi nel Jogo da Cabra Cega, per la sua funzione ipnotica, liberatrice dell'inconsciente bloccato dalla coercizione morale del Sistema sociale. Nella effabulazione narrativa, la funzione del "gruppo" risultante dalla moltiplicazione dell' "io" attaverso lo specchio, è effettuare lo scarico delle eccitazioni (energia e tensione) scatenatesi in Pedro Serra (= essere tormentato dalla stimolazione interna e esterna). Allo stesso modo, ogni compenente del "gruppo" è una maschera davanti allo specchio, che libera e realizza ii represso.

- Versão pela Professora Carolina Massi Albanese. 